\title{
TEORIA CRÍTICA E PESQUISA EMPÍRICA EM EDUCAÇÃO: A SALA DE AULA DE FÍSICA
}

\author{
W. F. GUIMARÃES*, E. G. RORIZ e R. A. V. TEIXEIRA \\ PUC Minas \\ freitasg@uol.com.br
}

Artigo submetido em agosto/2013 e aceito em abril/2014

DOI: $10.15628 /$ holos.2015.1571

\section{RESUMO}

O objetivo da pesquisa foi investigar o currículo materializado na sala de aula de Física, interpretando o que os dados nos revelaram, no processo de didatização do conhecimento, sobre a efetivação das diretrizes curriculares do ensino de Física. O pressuposto para a pesquisa é que o currículo materializado traduziria o sentido do ensino da Física no projeto pedagógico da modernidade, ou seja, como o ensino de Física favoreceria a realização das aspirações da Bildung. educar, ensinar e formar. A metodologia utilizada foi a Hermenêutica Objetiva, um procedimento de pesquisa empírica qualitativa e interpretativa, desenvolvido pelo sociólogo Ulrich Oevermann, que permitiu compreender a escola a partir da reconstituição da aula. A investigação apontou que a disciplina analisada na sala de aula não confirma a realização das diretrizes curriculares de um ensino de Física que promova a autonomia para o aprender a partir dos elementos próximos, práticos e vivenciais dos alunos. Em vários momentos, a aula sustentada no senso comum, em informações equivocadas e mesmo reducionistas resulta na semiformação e na falta de um ensino da Física abordado enquanto construção histórica, como atividade social humana na qual as teorias científicas mantêm uma relação complexa com o contexto social, político, econômico e cultural em que ocorreram. Fato que reforça um processo educacional de mitificação do conhecimento científico, por parte dos alunos e limita a atuação dos mesmos, como cidadãos ativos e críticos, capazes de emitirem juízos de valor em relação a situações sociais que envolvam aspectos físicos e/ou tecnológicos relevantes.

PALAVRAS-CHAVE: Teoria Crítica, Currículo, Sala de aula, Formação (Bildung), Indústria Cultural.

\section{CRITICAL THEORY AND EMPIRICAL RESEARCH IN EDUCATION: CLASSROOM OF PHYSICS}

\begin{abstract}
The goal of the research that originated this dissertation was to investigate the materialized curriculum in a Physics classroom, interpreting what the data revealed to us, in the process of didatization of knowledge about the effectiveness of the curriculum guidelines of physics teaching. The premise for the research is that the curriculum materialized, would express the sense of the teaching of physics in pedagogical project of modernity, ie, as the teaching of physics favor the realization of the aspirations of Bildung." The methodoly used was the Objective Hermeneutics, a procedure of qualitative and interpretative research, developed by the sociologist Ulrich Oevermann, that allowed us to understand the school from the reconstruction of the lesson. The study showed that the subject that was analised in the classroom doesn't confirm the accomplishment of the
\end{abstract}

KEYWORDS: Critical Theory, Curriculum, Classroom, Formation (Bildung), Culture Industry. 


\section{INTRODUÇÃO}

Desde os antigos, passando pelos medievos, aspirou-se a um conhecimento que se distinguisse do mito e do saber comum, mas foi somente pelas mãos de Copérnico, Galileu e Newton que ocorreu uma verdadeira revolução científica epistemológica e paradigmática na forma de se produzir conhecimento. A finalidade prática era a de criar um conhecimento capaz de instrumentalizar, controlar a natureza e constatar fatos. Assim, nesse ambiente cientificista, no contexto do século XIX, o positivismo de Comte reforçará o otimismo no conhecimento positivo ao exaltar a capacidade de transformação da sociedade em direção a um mundo melhor e ao progresso por meio do projeto da razão. A ideia de conhecimento científico era a de um saber acabado que colocava a ciência positiva como o ápice da vida e do conhecimento humanos.

Nessa perspectiva positivista do conhecimento sobre a realidade, desenvolveu-se uma mentalidade instrumental sintonizada com os estereótipos culturais hegemônicos de força, vitória e sucesso da sociedade capitalista. Sendo defendida a ideia de que o conhecimento científico positivo não admitiria conjecturas, dúvidas ou indeterminações. Nesse paradigma, o conhecimento produzido seria apresentado como verdade absoluta, conhecimento neutro, objetivo, natural, fixo e sem historicidade, ou seja, um mito.

Entretanto, se os conceitos e conhecimentos das Ciências permanecerem, nas escolas, como uma tradução lógica e racional da compreensão da realidade, isto é, o próprio real, o resultado será uma educação que reforçará os processos de mitificação da ciência, negando ao educando a possibilidade de um pensamento crítico com relação à função social da própria ciência, consolidando uma visão linear, evolutiva e natural do desenvolvimento do conhecimento científico. Situações pedagógicas que conduzem ao desaparecimento do potencial crítico, esclarecedor e criativo da educação negam, aos alunos, uma formação que possibilite entender a ciência como um campo da tradição e da autoridade organizada, sendo, portanto, imbricado de relações de poder. Sendo assim, negam a educação como uma exigência política na formação de pessoas emancipadas e a escola como um espaço de "pensar o pensamento", condição básica para se garantir aos alunos a possibilidade de desenvolverem a autonomia, tal como preconizado por Adorno na sua teoria crítica da sociedade.

Para Adorno (1995), a educação é uma condição para a autonomia não devendo modelar as pessoas ou limitar-se à mera transmissão de conhecimentos. Para ele, a educação deveria fortalecer a resistência e não fortalecer a adaptação. Em outras palavras, a educação deve conduzir o homem ao processo de formação, favorecendo o desenvolvimento de sua humanização, preparando-o para se orientar no mundo e capacitando-o para a autoreflexão crítica, indo muito além da reprodução de uma visão de ciência estagnada e estática, detentora de verdades absolutas, criando a imagem do cientista que tudo sabe e tudo pode. Como nos diz Vianna, "desvinculada de uma sociedade que cria esses conceitos científicos, muda-os e reinterpreta-os" (Vianna \& Pinto, 1994; p.80). Na perspectiva da Teoria Crítica é preciso romper com a fetichização do conhecimento científico, pretensamente neutro e universal, e refutar o fundamento epistemológico de que a objetividade da ciência radica, tão somente, na objetividade do método crítico. "Toda a produção da ciência está condicionada ao cumprimento de juízos de valores" (Zuin, 1999; p.45), pressuposto que, também, possui implicações 
educacionais no modo de se trabalhar com os conhecimentos e conceitos da Física das Ciências em sala de aula.

Se a escola reproduz, na sala de aula, uma visão simplista, operacional, técnica e enciclopédica sobre ciência, o conhecimento científico poderá ser aprendido como algo de valor inquestionável a ser transmitido aos alunos e não como reflexo da sociedade e da cultura do seu tempo, o que comprometerá a possibilidade de uma educação para a autonomia. Isso porque, no âmbito da prática educacional, os saberes dominantes reproduzidos em sala de aula se concentrarão apenas em questões técnicas e, a construção de conteúdos e conhecimentos, apenas em exposições didáticas meramente conceituais. Ou, quando muito, em treinamento do aluno em alguma destreza utilitária, voltada, tão somente, para os exames de vestibulares ou para o mercado de trabalho, deixando de lado aspectos que marcaram o desenvolvimento científico e que são importantes na formação autônoma, crítica, criativa e democrática do educando.

Se o ensino da Física, por exemplo, estiver voltado, tão somente, para a apresentação de conceitos,

leis e fórmulas, de forma desarticulada, distanciados do mundo vivido pelos alunos e professores, (...) em situações artificiais, desvinculando a linguagem matemática que essas fórmulas representam de seu significado físico efetivo, (...), insistindo na solução de exercícios repetitivos, pretendendo que o aprendizado ocorra pela automatização ou memorização e não pela construção do conhecimento (...) e ser apresentado como um produto acabado, fruto da genialidade de mentes como a de Galileu, Newton ou Einstein (Brasil, 1998; p.22).

certamente impedirá uma educação construtiva e crítica sobre a ciência e a prática científica, comprometendo na forma e na essência a formação integral do educando. Do ponto de vista educacional, não basta ter conhecimento científico sobre a natureza; também é necessário entender como a ciência funciona, pois só assim as características e limites deste saber podem ser avaliados. Assim, é essencial, no ensino das Ciências Físicas, uma abordagem e tratamento do conhecimento enquanto construção histórica, como atividade social humana que emerge da cultura, com vistas a levar, o educando, à compreensão de que os modelos explicativos científicos não são únicos e nem finais.

Acreditamos estar havendo uma revisão do paradigma científico até então dominante no século $\mathrm{XX}$, dando origem a uma ciência pós-moderna correspondente a uma "nova visão de mundo que tem reflexos enormes na metodologia e no desenvolvimento da Física" (Caruso \& Freitas, 2009, p.356). Do ponto de vista educacional, essa mudança introduz profundas modificações na abordagem do conhecimento da Física, bem como desdobramentos na evidência da equação que estabelecia a identidade entre a razão científica esclarecida e a humanidade emancipada. O postulado é que o conhecimento científico é falível na sua constituição e nas consequências que produz, dessa forma não permite se constituir em uma ideologia arbitrária e estática de mundo a ser reproduzida e ensinada formalmente na sala de aula apenas por meio da lógica positivista que prioriza o acúmulo de informações e valida como ciência apenas operações quantificáveis e previsíveis matematicamente. Sabemos, cada vez mais, da complexidade da realidade e que o desenvolvimento do processo educacional que se sustenta apenas por meio de um ensino científico instrumental, formal e pragmático, somente reforçará a 
mercantilização e a manutenção da ordem socioeconômica estabelecida, o status quo, não contribuindo para a formação integral do indivíduo e a transformação da realidade social.

É possível constatar que, os conhecimentos e conceitos da Física, ensinados na sala de aula, ao permanecerem como dogmas naturais, deixam de ser vistos como possíveis representações da realidade e transformam-se em um fim em si mesmo, em modelos explicativos únicos e finais. O que compromete uma educação propedêutica mais crítica e, sabidamente, mais adequada à formação da cidadania. Se o ensino da Física que se opera na sala de aula, insistir em permanecer dentro da lógica positivista e cientificista, onde prevalece o acúmulo de informações, excessivamente formais, e, sem historicidade, a educação para a autonomia estará comprometida porque contribuirá para a produção de mentes menos esclarecidas, apesar de mais instruídas. Provavelmente abarcará somente os conhecimentos e conceitos à luz dos parâmetros da utilidade e da operacionalidade, numa educação excessivamente formal e técnica. Essa situação educacional expulsará a reflexão da sala de aula, sobretudo, do caráter histórico e transitório da produção desse conhecimento. A consequência é a dogmatização dos saberes e a alienação do educando. Fato que anula, segundo Adorno (1995) uma concepção de educação para a contradição e resistência, ou seja, para a emancipação. 0 resultado será a semiformação.

\section{A TEORIA CRÍTICA}

Na semiformação, o domínio do saber, o conhecimento da cultura humana acumulado e a reflexão, sobre o próprio conhecimento, são tornados irrelevantes. Como consequência, segundo Adorno, a semiformação possibilita a adaptação e ao conformismo do educando diante da realidade social, tornando-o incapaz do exercício da crítica imanente. O resultado desse processo educacional será a legitimação e reprodução do estabelecido.

Há de se dizer que, embora Adorno não tenha pretendido, em nenhum momento, propor um projeto de educação, a clareza e a pertinência de suas reflexões filosóficas nos conduz a pensar em uma educação que não tolha o indivíduo em sua individualidade, em sua capacidade criativa e em sua autonomia, num processo de adequação e adaptação ao sistema social. 0 filósofo nos alerta sobre o possível risco de se anular a formação ética e reflexiva do processo educacional em função de sua determinação social e da pseudoformação.

Como vemos, é possível extrair da Teoria Crítica adorniana pistas de uma educação para a autonomia que privilegie a reflexão e que rompa com as facilidades do raciocínio condicionado a permanecer na superfície do dado imediato numa sociedade altamente administrada. Sua concepção de educação sinaliza sobre a necessidade de se colocar sub judice as aparências naturalizadas da vida social mercantilizada da sociedade capitalista que, por meio da Indústria Cultural, expropria o sujeito da sua autonomia. Aqui, percebe-se uma defesa radical do resgate da dimensão emancipatória da Bildung enquanto formação plena do indivíduo. Em Adorno, a formação (Bildung) é uma reivindicação última da educação.

Em sua Teoria Crítica, Adorno mostra temer os efeitos da semiformação, que tornaria as pessoas destituídas da autonomia, a qual foi suprimida na vida social sob o império da indústria cultural. Somente onde a formação represente a independência de pensamento é possível resistir aos ditames da ordem social exterior ao homem e, só por meio dessa condição, é possível 
a edificação de uma sociedade justa de homens livres. Para o pensador, quanto mais o ensino procurar se fechar ao seu condicionamento social, tanto mais a formação se converterá em mera presa da situação social existente contribuindo para educar pessoas apenas bem ajustadas. Seguindo esse ponto de vista, a educação ao privilegiar o enfoque positivista de seriação e compartimentalização dos conhecimentos, em que esses são apresentados como imóveis e imutáveis, neutros e imparciais e, sem historicidade, impede o avanço de um projeto emancipatório de educação que permita ao indivíduo transformar a realidade social na qual está inserido. Com efeito, se o processo educativo não pode ser abstraído do funcionamento da sociedade, desse modo, os conhecimentos ensinados na escola, não permitem ser trabalhados como se fossem objetivos, imparciais e divorciados do mundo dos valores, do mundo da cultura.

Para a Teoria Crítica, se faz necessário escapar aos ditames de um formalismo escolar e de uma educação uniformizante cujo "pensamento enrijecido, coisificado, cuja aparente precisão de lógica discursiva nos envolve com um encantamento" (Maar, 1995; p.14) acabando por autonomizar o conhecimento ao restringir a reflexão educacional sobre a realidade social, mascarando as relações de poder existentes. Um dos objetivos da educação é estimular os alunos a pensar o real, com toda a sua riqueza, mutabilidade e complexidade. Desse modo, uma análise da prática educacional revela que, na medida em que faz "a mediação de uma visão de homem e de mundo, a educação promove a razão formalizada, ou seja, a mesma razão que tem predominância na civilização ocidental. (...) Assim, verifica-se a legitimação dessa razão tanto pelos procedimentos pedagógicos (a seriação do saber, (...) a organização dos currículos privilegiando o enfoque positivista) como pelo próprio conteúdo, que autonomiza o conhecimento (...), ou seja, os conhecimentos trabalhados pela escola perdem seu vínculo com as exigências das necessidades sociais e atrelam-se a interesses de grupos que detêm o poder". (Prestes, 1995, p.97).

Se as reflexões de Adorno nos possibilita fazer essa leitura, importante se torna esclarecer que ele não desenvolveu uma proposta para a "emancipação" como um projeto de ação pedagógica. Assim, embora ele não seja um teórico da educação, sua obra sinalizou uma educação para a emancipação e uma reivindicação para a escola onde o ensino não pode ratificar a supressão do pensamento já operado na lógica social e, consequentemente, expropriar do homem a capacidade de reflexão fazendo com que a consciência fique coisificada.

Diante disso, torna-se fundamental pensar que toda a produção da ciência está condicionada ao cumprimento de juízos de valores e, portanto, os conhecimentos e conceitos da Física, ensinados em sala de aula, na perspectiva positivista e desistoricizada, deve ser combatido na educação, evitando-se fechar as portas dos processos reflexivos da própria experiência do educando, em uma explicação unívoca, fragmentada e simplificada dos conteúdos. É necessário romper com um processo educacional pautado meramente numa estratégia de "esclarecimento" da consciência.

Pelas razões expostas, a pesquisa que desenvolvemos, e cujos resultados conclusivos apresentamos, suscintamente, buscou investigar se na sala de aula de Física, o conhecimento prescrito, na estrutura do currículo escolar e reproduzido nos editoriais dos livros didáticos da disciplina e manuais, continua a ser ensinado, na sala de aula, pelo professor, como uma tradução lógica, racional e natural da compreensão da realidade; se o currículo prescrito, no planejamento, oculto e em ação, de Física, se constitui, na sala de aula, em um monumento inatacável do ponto de vista epistemológico e em um produto sem historicidade. Uma 
problematização de fundo foi pesquisar como os conteúdos de Física estiveram estruturados e, como foram ensinados na sala de aula. Esse empreendimento é extremamente pertinente, do ponto de vista da educação para a emancipação, pois é por meio da escola que se dá a legitimação de todos os processos que levam ao esclarecimento em todos os níveis, isto é, acadêmico, psicológico e emocional do indivíduo, com vista ao desenvolvimento da sua plena autonomia.

Assim, a sala de aula de Física foi o foco e o "lócus" de nossa investigação. É ela o lugar onde o professor e sua ação pedagógica dão materialidade às relações existentes entre a escola e a sociedade; onde as categorias autonomia \heteronomia operam dialeticamente no processo educacional espelhando qual é a relação dos professores e alunos com o conhecimento. Colocase em foco, na investigação empírica da sala de aula, a didática do professor, sua competência e formas de lidar com os conteúdos e com as situações particulares e coletivas dos sujeitos-alunos. É na sala aula onde se revela e se concretiza o ensino da Física e os processos de escolarização, os quais, por sua vez, revelam as possibilidades e limites de concretização, na escola e através dela, das aspirações da própria educação. A lida com o conhecimento é uma condição para que o processo educacional seja instaurado dentro da escola. Portanto, conhecer o que se passa dentre da sala de aula é uma condição para nosso conhecimento sobre os sentidos da educação, revelados em cada processo pedagógico instaurado pelas disciplinas.

À luz da Teoria Crítica buscou-se pensar a escola, revelar a dialética entre o ensino idealizado e o realizado na sala de aula de Física, desvendar o que foi a aula ao abarcá-la como objeto de análise. Dessa forma, pudemos chegar à sua compreensão final apenas após o descerramento dos seus muitos elementos aparentemente ocultos que foram revelados na pesquisa de campo e na análise. Parafraseando Adorno na Dialética Negativa, "o cofre se abriu após a descoberta do segredo da fechadura" (Adorno, 2009, p. 125). Desvelar, revelar, desvendar e contrastar a sala de aula de Física, com o que ela aparenta ser, dissecando o percurso entre a educação proposta e a educação que se efetivou em sala de aula é o que a pesquisa se propôs. Assim, buscou-se captar e interpretar as tensões, as possibilidades e os sentidos da realização do ensino de Física, na sala de aula de uma turma do Ensino Médio nas Minas Gerais. As questões norteadoras foram: como o ensino da Física era trabalhado, na sala de aula? Seria numa concepção de ciência a-histórica? Será que os alunos lidam com o conhecimento, produzido pela Física e seu Método, como um "monumento", ou seja, um conhecimento infalível, intocável e não suscetível às críticas e equívocos, fruto de construções teóricas finais e de verdades absolutas, num modelo mecanicista? Será que o conhecimento da Física é reproduzido, na sala de aula, na lógica positivista? Como era a abordagem dos conteúdos\conceitos da Física em sala de aula? Eles contribuem para uma educação enquanto processo de formação?

Tendo em vista buscar respostas à problemática, a pesquisa investigou se no processo de didatização do conhecimento que se instalou na sala de aula, os conhecimentos e as experiências relacionais, estabelecidas na aula de Física, permaneceram atreladas a um discurso mediado pela linguagem da lógica positivista ou permitiram, ao educando, uma aprendizagem significativa de conteúdos e significados da Ciência que contribuam para sua formação integral. Considerando que esta é a função da Educação. Para tanto, foi utilizada a metodologia da Hermenêutica Objetiva. 


\section{A METODOLOGIA}

A Hermenêutica Objetiva constitui em uma concepção de pesquisa qualitativa em Educação por se tratar de uma proposta metodológica de coleta, análise e interpretação dos dados empíricos. A metodologia foi desenvolvida por Oevermann e busca desvendar situações da vida social, no nosso caso a sala de aula, reconstituindo o processo de interação estabelecido. A ideia é captar, no processo estabelecido na sala de aula, os aspectos dialéticos subjetivos e imanentes. No âmbito da metodologia qualitativa, a interpretação hermenêutica busca reconstruir os processos interativos que produzem o sentido prático ou a construção social da realidade. Nesse sentido, o método busca operar de forma reconstrutiva para fazer emergir as estruturas latentes da sala de aula de Física, objetivando-as. Nessa reconstrução das estruturas, partimos da singularidade de análises concretas de pequenas partes, buscando apreender a manifestação radical na particularidade do objeto estudado, com vista ao entendimento do todo analisado. Quanto mais se avança na análise sequencial de uma realidade singular de uma aula, por exemplo, mais se explica o contexto interno de reprodução da estrutura da aula. Assim, a Hermenêutica Objetiva é um procedimento de pesquisa qualitativa e interpretativa que realiza a análise hermenêutica de textos com a pretensão de encontrar a validade da interpretação. Os textos escritos, que apresentam fidedignamente a situação captada em pesquisa de campo, são chamados de "protocolos". Eles registraram os dados coletados para a pesquisa e, posteriormente foram analisados e interpretados pelo grupo de trabalho que tem, sempre, a presença de um ou mais especialistas da disciplina.

Definido esse aspecto da metodologia, é fato que a utilização do atributo "objetivo" não diz respeito somente ao objeto estudado, mas também à validade da interpretação, pois essa é realizada por meio de determinados procedimentos que não identificam a objetividade como uma realidade dada a ser capturada pela teoria. Nessa perspectiva, a Metodologia mantém o distanciamento da orientação positivista de pesquisa social.

A pista metodológica para se operar com a Hermenêutica Objetiva é a Teoria Crítica adorniana, pois, segundo ela, é preciso criar tensão entre aquilo que é aparente e aquilo que é real. Dessa forma, segundo Oevermann, citado por Vilela, o objetivo central da pesquisa Hermenêutica Objetiva é desvendar e tensionar a realidade, interpretando-a. Para que isso seja feito, a metodologia desenvolvida por Oevermann procura assegurar a validade da interpretação operando segundo algumas regras e alguns princípios. Um dos princípios diz respeito à forma de conceber a relação sujeito e objeto. Segundo Oevermann, o pesquisador deve ter o controle da sua subjetividade ao procurar se afastar de uma análise do objeto sustentada na projeção, esta entendida como uma interpretação do sujeito de forma espontânea e imediata. Ele não deve cair a priori sob o objeto de pesquisa numa síntese arbitrária classificatória porque essa forma de proceder torna-se ideologia; por sua vez, a identificação do pesquisador com o objeto torna-se idealização.

Isto é, se conceitualmente a Hermenêutica Objetiva de Oevermann está centrada na interpretação de textos escritos, os chamados protocolos feitos sobre o objeto de pesquisa, contudo, nesse procedimento, o imediato é percebido não mais como uma situação dada inquestionável mas sim revelado. Assim sendo, os protocolos, por sua vez, tal como revelados na pesquisa de campo, devem estar registrados fielmente, evidenciando passo a passo o acontecido. Por exemplo, o protocolo de uma aula deve registrar tudo o que ocorreu durante os 50 minutos 
da aula. E, antes de ser levado para a análise interpretativa, deve ser revisto pelo pesquisador, tanto a gravação, quanto a transcrição. O texto como elemento de análise deve informar fidedignamente o dado registrado e, no caderno de campo, deve está registrado todas as informações coletadas sobre a aula. Para a operação procedimental das análises é preciso seguir, rigorosamente, cinco regras ou estratégias, se atendo tanto aos princípios teóricos quanto aos procedimentos metodológicos.

A primeira regra refere-se à independência do contexto: nesse procedimento, a interpretação deve ater-se ao registrado no protocolo e pressupõe uma interpretação sequencial do texto, ou seja, de segmento em segmento, sem pressa. É o texto escrito que deve revelar o sentido da situação analisada. O que equivale a dizer que, nesse momento da análise, o pesquisador deve desconsiderar tanto as informações do contexto quanto as informações genéricas, não podendo explicar situações registradas no protocolo que está sendo analisado com esclarecimentos buscados no contexto, ou seja, não se permite introduzir informações anteriores sobre a situação analisada. $O$ intérprete não deve balizar sua análise em informações do contexto, por exemplo, justificar uma ação do professor na sala de aula com base na Instituição que o formou, ou por modismo pedagógico dele ou outras explicações que não estejam registradas no protocolo de análise. Apenas o texto escrito deve revelar o sentido da situação analisada. Cada interpretação somente pode ser validada no próprio texto. Cada passagem do texto deve ser esclarecida com a pergunta: o que está explicitado aqui (isso é, nesse registro, da forma em que se encontra). O conhecimento do contexto será importante para a análise final porque toda estrutura é produzida num contexto social que não permite ser descartada.

A segunda regra diz respeito à literalidade: o pesquisador deve decifrar o que está rigorosamente escrito e não tentar desvendar o que foi pensado pelos sujeitos da ação que estão em análise. O que está escrito foi expresso numa relação social, numa situação e tem um sentido ter sido expressado daquela forma. O intérprete não pode fazer projeções na análise do texto escrito. A interpretação literal do texto deve tomar como análise tão somente o que está escrito e não suposições teóricas, retiradas muitas vezes dos contextos sociais.

A terceira regra constitui-se no que chamamos de sequencialidade: essa é uma dimensão interna do método. Os protocolos de aulas da pesquisa empírica devem ser analisados e interpretados desde a primeira palavra registrada, cada frase, do começo ao fim. Na análise, é importante considerar os detalhes porque eles podem revelar aspectos importantes na reconstrução do fato analisado. A reconstrução do fato está ancorada na possibilidade de acompanhamento da cadeia das informações que estão registradas; essa cadeia revela as ligações, os sentidos do que foi ali selecionado.

A quarta regra diz respeito à substancialidade da informação: Para isso, torna-se necessária a formulação de afirmativas hipotéticas, buscando a compreensão dos dados a partir das múltiplas visões e explicações de cada membro da equipe acerca do que foi registrado. A interpretação procura responder a um sentido lógico, como cada situação registrada faz sentido dentro da situação, como se liga frases e situações anteriores do registro, o que é possibilitado pela equipe de profissionais de várias áreas do conhecimento para análise dos dados. $\mathrm{O}$ que se procura não é o consenso entre as diferentes explicações hipotéticas, mas a explicação mais plausível pela equipe de intérpretes. 
A quinta regra refere-se à parcimônia: deve-se realizar a análise a partir de fatos dos dados coletados, evitando-se incluir ou imaginar situações que ali não estão expressas, o que possibilita uma leitura da realidade da aula de forma mais objetiva, rigorosa e fidedigna. Ou seja, deve-se renunciar ao fictício, considerações exóticas e ao improvável. Além disso, é preciso ter paciência e parcimônia na condução da interpretação. Esses cuidados impedem conclusões apressadas e interpretações infundadas. Nesse sentido, afirmações quando ausentes no texto, não constituem objeto de interpretação hermenêutica.

Seguindo esses procedimentos de análise interpretativa, o pesquisador terá condições de chegar ao conhecimento sobre o objeto que está sendo investigado, revelando sua realidade.

Portanto, entender essa relação, como ela aconteceu em sala de aula, foi condição para se conhecer as contradições existentes entre aquilo que a escola pesquisada almeja ser, do ponto de vista educacional, com o que ela é, efetivamente. Foi por meio do desvendamento das tensões existentes entre a educação idealizada, suas aspirações, e o que efetivamente aconteceu na sala de aula, durante os processos didáticos pedagógicos de mediação do conhecimento, que apresentaremos as conclusões, não definitivas e universalizantes, para as questões problematizadoras que deram origem à pesquisa.

\section{CONCLUSÕES}

À guisa das conclusões, feito esse percurso de tensionar o aparente e o real, os estudos críticos e as análises apresentadas sinalizaram que o ensino da Física não esteve voltado para a formação de um cidadão contemporâneo, crítico e capaz de transformar o conhecimento adquirido em uma ferramenta a mais em suas formas de pensar e agir, portanto, em uma educação erigida para a edificação da autonomia do aluno e de sua criatividade. Muitos dos conteúdos foram desenvolvidos sem a participação efetiva do aluno. É necessário que se dê voz ativa ao aluno, na sala de aula, tendo em vista a participação e reflexão que vá além da reprodução dos conteúdos conceituais. Nesse sentido, o acesso ao conhecimento, por parte do aluno, constitui uma possível ferramenta de intervenção e não de reprodução da realidade social massificada pela Indústria Cultural.

O que se observou foi uma condução didática excessivamente formalista e pragmática, voltada para os exames de vestibulares, para as exigências do mercado e calcada na mera transmissão e memorização dos conteúdos. Desse modo, é possível afirmar que, as relações estabelecidas, na sala de aula, durante o processo de didatização do conhecimento, não garantiram a efetivação da Bildung. Isto porque os alunos não foram desafiados a buscarem aprender cada vez mais, condição para o pensamento autônomo e, portanto, para o exercício pedagógico de reflexão e de questionamento, imprescindíveis à formação integral.

As cenas das aulas analisadas revelaram ainda que o ensino da Física negou aos alunos a crítica com relação à função social da própria ciência ao consolidar uma visão natural do desenvolvimento científico e ao apresentar a teoria científica como um resultado de mentes brilhantes dos cientistas e, não como construção e possibilidade de explicações e interpretações da realidade. Se para a área de "Ciências da Natureza", na qual a Física está inserida, um dos objetivos é o desenvolvimento de conhecimentos práticos, contextualizados, que respondam às necessidades da vida contemporânea, visando o exercício da cidadania, essas dimensões não 
apareceram nas aulas, pois, o que prevaleceu, foi um ensino impregnado de exposições conceituais, voltadas tão somente à instrução e memorização de conceitos e fórmulas. O domínio do saber e a reflexão, sobre o próprio conhecimento, tornaram-se irrelevantes. Situação educacional que corroborou para a adaptação e o conformismo do educando diante da realidade social porque uma educação voltada para a formação integral somente se consolida a partir da construção significativa da relação do conhecimento com a realidade, na qual, o discurso científico, revela-se enquanto representação sobre o real, sem, no entanto, se confundir com ele.

Ademais, não se verificou uma sistematização de uma educação contextualizada e de um trabalho educativo capaz de orientar o aluno na construção do conhecimento, articulado a sua vivência. E, tão pouco, uma educação e formação que desenvolvesse, no educando, uma leitura dos conceitos\conhecimentos, produzidos pela Física, como um processo cuja construção ocorreu ao longo da história da humanidade, impregnado de contribuições culturais, econômicas e sociais, portanto, conhecimentos transitórios e, também, suscetíveis a erros e equívocos. $\mathrm{O}$ que sugere, em parte, por que os discursos dos alunos reproduzem uma visão estática e quase dogmática de ciência. Em diversas cenas da aula, o processo educativo foi conduzido de tal forma que a indisciplina tomou conta da sala de aula sem que o professor fizesse interferência. Há aulas nas quais, num longo espaço de tempo (pode chegar a 30 minutos) não foi possível sequer saber sobre o tema ou assunto desenvolvido. Em muitas cenas de aula os alunos não foram conduzidos para a superação de conhecimentos sedimentados pelo senso comum. Há situações onde a terminologia própria do conteúdo, tratado na aula, não esteve presente na linguagem dos alunos e nem na do professor. Há aulas com circulação de informações erradas, tendenciosas, com circulação de meias verdades, discursos ideológicos sem oportunidade de discussão. Encontramos situações de aulas em que predomina o "discurso do professor" sobre o tema sem a experiência prática efetiva com a Física. Em outras cenas das aulas analisadas o discurso recorrente de que os alunos não querem aprender e não estudam foi contradito com perguntas dos alunos. Às vezes o professor negava em respondê-las.

Há cenas de aulas, onde o professor pergunta aos alunos e ele mesmo apresenta a resposta, utilizando de analogias, como exemplos infelizes, não esclarecendo o entendimento. As cenas revelaram ainda que a sala de aula tornou-se um espaço em que o conhecimento não circulou e onde a autoridade do professor não existiu. Verificou-se nas cenas das aulas, carteiras se arrastando, falas eróticas, risos e muitas conversas paralelas. O professor utilizou-se de uma linguagem informal e perguntou se havia dúvida em relação ao para casa, ignorando a algazarra, num gesto de retórica. Sua preocupação foi passar mais para casa para os alunos. Não foi tirar as dúvidas dos alunos, sendo um mediador do processo de aprendizagem. Em algumas aulas a situação esteve incontrolável do ponto de vista disciplinar, o que comprometeu uma aprendizagem mais significativa, participativa e interativa. No entanto, o professor não fez nenhuma reflexão com a turma e nenhuma intervenção mais efetiva que garantisse, por direito, o acesso ao conhecimento dos alunos mais interessados ou daqueles que apresentassem dúvidas.

Em vários momentos, a aula foi sustentada no senso comum, em informações equivocadas e mesmo reducionistas, sugerindo a sedimentação da semiformação dos alunos ao negá-los a crítica com relação à função social da própria ciência e ao consolidar uma visão linear, evolutiva e natural do desenvolvimento do conhecimento científico. Uma educação significativa, participativa, proveitosa e útil para vida, metodologicamente bem conduzida, não esteve 
presente na aula. O professor passou informações superficiais de conteúdos formais e vazios aos alunos, fazendo do ensino um simples exercício mecânico de memorização de conceitos e leis, sem relação alguma com a realidade do educando. Podemos inferir que a Física que entrou em sala de aula não foi nem a tradicional, no modelo tipicamente cartesiano, e nem uma Física que fomentasse nos alunos uma leitura crítica em relação à função social da própria ciência. $A$ aula negou a lida dos alunos com a Física enquanto um campo de conhecimento contextualizado.

Desse modo, foi possível confirmar que entre o discurso daquilo que a educação se propõe, consubstanciado no Projeto Político Pedagógico da escola e nos PCNs e, as práticas de ensino, há um longo percurso a ser percorrido com vista a uma educação voltada para a reflexão e o desenvolvimento da criticidade dos alunos.

Finalmente, se constata que, os conhecimentos\conceitos da Física, ao permanecerem positivistas e mecanicistas, centrados na formalidade e compartimentalizados, não conduziram os alunos a uma educação para a autonomia.

\section{REFERÊNCIAS BIBLIOGRÁFICAS}

1. ADORNO, Theodor W. Educação e emancipação. Tradução Wolfgang Leo Maar. Rio de Janeiro: Paz e Terra, 1995.

2. ADORNO, T. W. Dialética negativa. Tradução Marco Antônio Casanova. Rio de Janeiro: Jorge Zahar, 2009.

3. ALMEIDA, Jorge de; LASTÓRIA, Luiz A. Calmon Nabuco. Experiência formativa e emancipação. São Paulo: Nanquin Editorial, 2009.

4. ANDERY, Maria Amália et al. Para compreender a ciência. São Paulo: EDUC, 1988.

5. BRASIL. PCN + Ensino Médio: orientações educacionais complementares aos parâmetros curriculares nacionais. Brasília: MEC, SEMTEC, 2002. Disponível em: <http://www.sbfisica.org.br/arquivos/PCN_FIS.pdf>. Acesso em: 22/03/2013.

6. BRASIL. Parâmetros Curriculares Nacionais. Brasília, Parte III. Ciências da Natureza, Matemática e suas Tecnologias. SEMTEC/MEC. Disponível em: portal.mec.gov.br/ seb/arquivos/pdf/ciencian.pdf. 1998. Acesso em: 25/07/2013.

7. CARUSO, Francisco; FREITAS, Nilton de. Física moderna no ensino médio: o espaço de Einstein em tirinha. In: Caderno Brasileiro de Ensino de Física. Florianópolis, v. 19, n. 1, 2009.

8. FORQUIN, Jean-Claude. Escola e cultura: as bases sociais e epistemológicas do conhecimento escolar. Porto Alegre: Artes Médicas, 1993.

9. MAAR, Wolfgang Leo. A guisa de introdução: Adorno e a experiência formativa. Rio de Janeiro: Paz e Terra, 1995.

10. PRESTES, Nadja Hermann. A razão, a teoria crítica e a educação. Petrópolis: Vozes, 1994.

11. PUCCI, Bruno. Teoria crítica e educação: a questão da formação cultural na Escola de Frankfurt. São Carlos: EDUFISCAR, 1994.

12. RAMOS, Newton de Oliveira. A escola, esse mundo estranho: teoria crítica e educação. São Carlos: Vozes, 1994.

13. SANTOS, Boaventura de Souza. Introdução a uma ciência pós-moderna. Rio de Janeiro: Graal, 
1989.

14. VIANNA, Deise Miranda; PINTO, Kátia Nunes. Caderno Catarinense de Ensino de Física. Florianópolis, vol. 11, n.2, 1994.

15. VILELA, Rita Amélia Teixeira; NOACK, Juliane. A pesquisa sociológica hermenêutica objetiva": novas perspectivas para a análise da realidade educacional e de práticas pedagógicas. Caxambu, 2008. Disponível em: < seer.bce.unb.br/index.php/linhascriticas/article/ download/.../2625> Acesso em 30 nov. 2011.

16. VILELA, Rita Amélia Teixeira. A presença da Teoria Critica no debate e na pesquisa educacional no Brasil e na Alemanha no período de 1995 à atualidade. Belo Horizonte: PUC Minas. Programa de Pós Graduação em Educação, Relatório de Pesquisa, 2009. Disponível em

http://www.pucminas.br/imagedb/mestrado_doutorado/publicacoes/PUA_ARQ_ARQUI201 20828095538.pdfr>. Acesso em: 30 nov. 2009.

17. VILELA, Rita Amélia Teixeira. Teoria crítica e pesquisa empírica na educação: a metodologia hermenêutica objetiva para análise da escola contemporânea. In: PUCCI, B. ZUIN, A. LASTORIA, L.A. Teoria crítica e inconformismo: novas perspectivas de pesquisa. Campinas: Autores Associados. 2010.

18. VILELA, Rita Amélia Teixeira. Estudo da sala de aula com aporte teórico-metodológico da hermenêutica objetiva. Disponível em: <http://www.pucminas.br/imagedb/mestrado_doutorado/publicacoes/PUA_ARQ_ARQUI20 120828100151.pdf> Joao Pessoa, novembro de 2011.

19. ZUIN, Antônio Álvaro Soares. Indústria cultural e educação: o novo canto da sereia. Campinas, SP: Autores Associados, 1999. 